\title{
Postpartum intrauterine contraceptive device: evaluation of acceptance and complications
}

\author{
Sindhu S. Gaur*, Suman Mendiratta
}

Department of Obstetrics and Gynecology, SMS Medical College, Jaipur, Rajasthan, India

Received: 28 May 2019

Accepted: 02 July 2019

*Correspondence:

Dr. Sindhu S. Gaur,

E-mail: sindhugaur9637@gmail.com

Copyright: (C) the author(s), publisher and licensee Medip Academy. This is an open-access article distributed under the terms of the Creative Commons Attribution Non-Commercial License, which permits unrestricted non-commercial use, distribution, and reproduction in any medium, provided the original work is properly cited.

\begin{abstract}
Background: Postpartum intrauterine contraceptive device is inserted within 10 minutes to 48 hours of expulsion of placenta. The objective of the study was to determine acceptability, safety and complications of PPIUCD in tertiary care center.

Methods: This is a retrospective study conducted at Zenana Hospital, SMS Medical College, Jaipur over a period of 1 year from April 2018 to March 2019. Women were followed after 6 weeks and their complaints and various parameters were analyzed.

Results: 5653 women were inserted PPIUCD during 1 year period. Acceptance rate was $29.26 \%$ and higher in multipara $(54.30 \%)$ and between 18 to 25 years of age $(50.29 \%)$. The main complaints at follow-up were pain and bleeding which were dealt mainly by reassurance. Main cause of removal was bleeding, pain and family pressure.

Conclusions: The acceptance was high in this study group. PPIUCD is safe, effective and acceptable with negligible side effects. PPIUCD has abundant scope in India where accessibility for contraception is lower during interval period and women do not come for follow-up after delivery.
\end{abstract}

Keywords: Acceptance, Awareness, Complications, Counseling, PPIUCD, Removal

\section{INTRODUCTION}

Immediate postpartum period is golden time for counselling for family planning. Increased institutional deliveries due to introduction of JSY and JSSK give us an opportunity to provide women easy access to immediate PPIUCD services. This is particularly important for a woman who has limited access to medical care services.

India is the second most populous country of the world having $17.5 \%$ of world's population in only $2.4 \%$ of global land mass. This large population size of India not only impacts its own but also global health indicators. WHO in 1971 defined family planning as "A way of thinking and living that is adopted voluntarily upon on the basis of knowledge attitudes and responsible decision by individuals and couples in order to promote the health and welfare of the family group and thus contribute effectively to the social development of a country". ${ }^{1}$

Previously postpartum birth control measures counselling were delayed until 6 weeks postpartum visit and women was advised to come for family planning advice after 6 weeks postpartum period and by this time women were put at risk for unintended pregnancy and majority does not even come for follow-up. Women who deliver by caesarean section may be more likely to resume sexual activity earlier than women who had vaginal deliveries. ${ }^{2-4}$ 
Cochrane reviews provide evidence of safety and feasibility of postpartum IUCD insertion in various settings. ${ }^{5}$

Immediate PPIUCD insertion is labelled when intrauterine device is inserted within 10 minutes to 48 hours of expulsion of placenta. At this time the women would prefer to avoid pregnancy and are highly motivated to use contraceptive measures. High level of acceptance may be achieved by proper counselling during this period. However acceptance rate can be increased more if counselling has been started during antenatal visits.

PPIUCD does not interfere with breastfeeding and allow women to obtain safe, long acting, highly effective contraception. ${ }^{6}$ Other advantage is that the discomfort related to interval insertion can be avoided and any bleeding from insertion will be disguised by lochia. ${ }^{7}$

It is safe, one time application, inexpensive, reversible, acceptable, simpler to administer, independent of coitus, require no or little medical supervision and serve as both limiting and spacing in same cases. ${ }^{8}$

However, PPIUCD insertion may increase the risk of adverse events such as perforation, pain, and bleeding as well as spontaneous expulsion. ${ }^{9}$

In our country PPIUCD are still emerging as relatively new contraception choice.

The aim of the study is to evaluate acceptability, safety, efficacy and complications of PPIUCD at tertiary care centre.

\section{METHODS}

This retrospective study was conducted in Department of Obstetrics and Gynaecology at SMS Medical College, Jaipur for duration of 1 year from April 2018 to March 2019. This study included women who were admitted and delivered vaginally or by LSCS and inserted PPIUCD.

\section{Inclusion criteria}

- All women delivering vaginally or by caesarean section, counseled for PPIUCD insertion during antenatal period as well as in latent phase of labour. Written and informed consent was obtained from those, who opted for insertion.

\section{Exclusion criteria}

- $\quad$ Age - 18-45 years

- Gestational age 34-40 weeks

- No infection

- $\mathrm{Hb} \geq 8 \mathrm{gm} / \mathrm{dl}$

- No medical illness - diabetes mellitus and hypertension

\section{Exclusion criteria}

According to medical eligibility criteria for IUCD by WHO:

- Fever during labour or delivery $\left(\mathrm{Temp}>38^{\circ} \mathrm{C}\right)$

- Active STD or other genital tract infection or high risk for STD

- Ruptured membrane $>18$ hours prior to delivery

- Known uterine abnormality e.g. bicornuate, septate uterus, uterine myomas

- Manual removal of placenta

- Unresolved postpartum haemorrhage requiring use of additional oxytocic agents in addition to AMTSL.

\section{The type of insertion}

\section{Post-placental}

Immediately following delivery of placenta IUCD was inserted within 10 minutes.

\section{Intra-caesarean}

During caesarean section IUCD was inserted through the uterine incision and placed at the uterine fundus after placenta was removed and then uterine incision was closed.

On discharge women were advised to visit after 6 weeks or prior if any complaint occurs. On follow-up women were examined for:

- Whether she came in at the six week schedule or earlier due to any complaint

- On per-speculum examination if IUCD thread were long, they cut $2 \mathrm{~cm}$ from external os

- If IUCD thread not seen and there was no history of expulsion ultrasound was performed for confirmation of IUCD in place

- Women who didn't came for follow-up telephonically contacted and information was collected.

The observations were noted and analyzed. Various parameters analyzed were age, parity, type of application, spontaneous expulsion, manual, reason for removal and complications.

\section{RESULTS}

Total number of deliveries during the period of April 2018 to March 2019 was 20239. Out of these 19319 women were included in the study group and offered PPIUCD insertion.

5653 (29.3\%) accepted PPIUCD insertion. 37.06\% $(\mathrm{n}=2095)$ women had IUCD insertion during caesarean section while $62.94 \% \quad(n=3558)$ women after vaginal 
delivery. Acceptance of PPIUCD was more after vaginal delivery as compared to caesarean section (Table 1).

Table 1: Timing of PPIUCD insertion.

\begin{tabular}{|lll|}
\hline PPIUCD insertion & No. of women & Percentage \\
\hline Post placental & 3558 & $62.94 \%$ \\
\hline Intra-caesarean & 2095 & $37.06 \%$ \\
\hline
\end{tabular}

Most of the women were aged between 18-25 years. PPIUCD acceptance was 50.29\% $(\mathrm{n}=2843)$ in $18-25$ years of age group while it declined to $38.33 \%(n=2167)$ between 26-30 years and remained only $2.26 \% \quad(n=128)$ after age of 35 years. Acceptance was more in younger age group of women which gradually declined with increasing age (Table 2).

Table 2: Acceptance of PPIUCD among different age groups.

\begin{tabular}{|lll|}
\hline Age (in years) & No. of women & Percentage \\
\hline $18-25$ & 2843 & $50.29 \%$ \\
\hline $26-30$ & 2167 & $38.33 \%$ \\
\hline $31-35$ & 515 & $9.11 \%$ \\
\hline$>35$ & 128 & $2.26 \%$ \\
\hline
\end{tabular}

The acceptance was higher in multiparous women $54.30 \%(\mathrm{n}=3070)$ as compared to primiparous women $45.69 \%(n=2583)$, which was similar to study by Grimes et al where they found higher acceptance in multiparous women $(65.1 \%)$ (Table 3$).^{5}$

Table 3: Acceptance among primipara and multipara.

\begin{tabular}{|lll|}
\hline Parity & No. of women & Percentage \\
\hline Primipara & 2583 & $45.69 \%$ \\
\hline Multipara & 3070 & $54.30 \%$ \\
\hline
\end{tabular}

Not all the women are coming back for follow-up at our tertiary centre as many were unbooked and came through emergency, some were contacted telephonically and data collected. Most of the follow-up in our hospital are clinical follow-up.

Table 4: Main complaints at the time of follow-up.

\begin{tabular}{|ll|}
\hline Complaint & Percentage \\
\hline Lower abdominal pain & $16.10 \%$ \\
\hline Excessive bleeding & $12.64 \%$ \\
\hline Long thread & $6.10 \%$ \\
\hline Missing thread & $11.63 \%$ \\
\hline Removal & $3.80 \%$ \\
\hline Expulsion & $5.55 \%$ \\
\hline
\end{tabular}

Most of the complaints were dealt by assurance. Expulsion rate was $5.55 \%$ and removal rate was $3.80 \%$ but it cannot be calculated accurately as some acceptors did not come for follow-up and also could not be contacted telephonically. The main causes for removal of PPIUCD were bleeding and family pressure (Table 4).

\section{DISCUSSION}

Postpartum IUCD insertion is an opportunity not to be missed in developing countries like India, where this is the only time when many women come in contact with health care providers and can be counseled easily and women are highly motivated to initiate contraceptive use.

In this study acceptance was $29.26 \%$. We found that acceptance rate was higher among age group of 18-25 years $(50.29 \%)$ which is comparable to studies done by Kathekit $\mathrm{G}$ et al and Mishra S, acceptance rate decreases as age increases and remains only $2.26 \%$ after age of 35 years. ${ }^{10,11}$

In present study acceptance rate for postplacental IUCD insertion was (62.94\%) and for intra-caesarean $(36.06 \%)$ which is similar to study done by Kumar $\mathrm{S}$ et al, where one third of the insertion were during caesarean section and study done by Rani K et al. ${ }^{12,13}$

Acceptance for PPIUCD was higher in multipara women $(54.30 \%)$ than primipara a woman $(45.69 \%)$ which is similar to study by Grimes et al and Shobhesmita B et al, but it does not correlate with study done by Malchuru $\mathrm{S}$ et al, Gautam $\mathrm{R}$ et al and Vidyarama $\mathrm{R}$ et al where acceptance for PPIUCD was more in primipara. ${ }^{14-17}$ In this study on follow-up $16.10 \%$ women were complaining of abdominal pain that was similar to study done by Chen et al. ${ }^{18}$ In this study $12.64 \%$ women had excessive vaginal bleeding which is comparable to study done by Mishra $\mathrm{S}$ and Sunita $\mathrm{S}$ et al, where menorrhagia was found in $25.5 \%$ and $13.04 \%$ women respectively. ${ }^{19,20}$

In present study incidence of missing thread was $11.63 \%$ which is comparable to study done by Shukla $\mathrm{M}$ et al and Mishra S et al. ${ }^{7,11}$ In present study $5.55 \%$ women had expulsion of PPIUCD which is similar to study done by Mishra $S$ et al and Shobhesmita et al who found expulsion rate to be $6.4 \%$ and $6 \%$ respectively. In present study removal rate was $3.80 \%$ after reassurance and counselling. ${ }^{7,14}$

The limitation of the study was the lost to follow-up cases where about $40 \%$ cases could not be followed-up although some contacted on telephone.

\section{CONCLUSION}

The acceptance of PPIUCD was high in the present study. Postpartum intrauterine contraceptive device appears to be safe, effective, acceptable, convenient, cost-effective, reversible method of contraception with negligible rate of expulsion, pelvic infection and other complications.

Regular and repeated antenatal counselling of couple can increase awareness and acceptance of PPIUCD Training 
of health care providers for PPIUCD and motivation by them to pregnant women and her family members can further increase acceptance rate.

\section{ACKNOWLEDGMENTS}

Authors would like to thank the patients, hospital staff, family planning staff, nurses and Asha workers and ANM's for their participation in this study.

\section{Funding: No funding sources}

Conflict of interest: None declared

Ethical approval: Not required

\section{REFERENCES}

1. World Health Organization. Technical Report Series No. 483; 1971. Available at: apps. who.int $>$ iris $>$ bitstream $>$ handle. Accessed on $28^{\text {th }}$ May, 2019.

2. Speroff L, Mishell DR. The postpartum visit: its time for a change in order to optimally initiate contraception. Contracept. 2008;78:90-8.

3. Barrett G, Peacock J, Victor CR, Manyonda I. Caesarean section and postnatal sexual health. Birth. 2005;32:306-11.

4. Khajehei M, Ziyadiou S, Safari RM, Tabatabaee H, Kashefi F. A comparison of sexual outcomes in primiparous women experiencing vaginal and caesarean births. Indian $\mathbf{J}$ Community Med. 2009;34:126-30.

5. Grimes DA, Lopez LM, Schulz KF, Van Vliet HA, Stanwood NL. Immediate postpartum insertion of intrauterine devices, Cochrane Database Syst Rev. 2010;5:CD003036.

6. Family Planning Division, Ministry of Health and Family Welfare, Government of India : Postpartum IUCD reference manual, 2010. Available at: www.nrhmtn.gov.in>modules> PPIUCD. Accessed on $28^{\text {th }}$ May 2019.

7. Shukla M, Qureshi S, Chandrawati. Postplacental intrauterine device insertion - a five year experience at a tertiary care centre in north India. Indian $\mathbf{J}$ Med Res. 2012;136:432-5.

8. Akkuzu G, Vural G, Eroglu K, Dilbaz B, Taskin L, Akin A, et al. Reason for continuation or discontinuation of IUD in post placental/early postpartum periods and post puerperal/interval periods. One year follow up. Turkiye Klinikleri J Med Sci. 2009;29:353-60.

9. Kopp N, Curtis KM. Intrauterine device Insertion during the postpartum period a systemic review. Contracept. 2009;80:327-36.

10. Katheit G, Agarwal J. Evaluation of post placental intrauterine contraceptive device (PPIUCD) in terms of awareness, acceptance and expulsion in a tertiary care centre. Int J Reprod Contracept Obstet Gynaecol. 2013;2:539-43.

11. Mishra S. Evaluation of safety, efficacy, and expulsion of post-placental and intra-cesarean insertion of intrauterine contraceptive devices (PPIUCD). J Obstet Gynaecol India. 2014;64:33743.

12. Kumar S, Sethi R, Balasubramaniam S, Charurat E, Lalchandani K, Semba R, et al. Women's experience with postpartum intrauterine contraceptive device use in India. Reprod Health. 2014;11:32.

13. Rani K, Pangtey NK, Khanna G, Rani M. Postpartum intrauterine contraceptive device (PPIUCD) insertion: practices and aftermath at tertiary care centre. Int J Reprod Contracept Obstet Gynecol. 2018;7(11):4742-6.

14. Shobhasmita B, Anupal S, Alakananda D, Bhattacharjee A, Nabnita D. Acceptance of postpartum intrauterine contraceptive device among women attending Gauhati Medical College and Hospital for delivery between January 2011 to December 2014 and their follow up. J Evol Med Dent Sci. 2015;4:15756-8.

15. Malchuru S, Arun V, Prabhavathi N. Postpartum intrauterine device insertion- 2 years' experience at tertiary care centre in Gunture Medical College/Govt general hospital, Guntur. J Dent Med Sci. 2015;14:56-61.

16. Gautam R, Arya KN, Kharakwal S, Singh S, Trivedi M. Overview of immediate PPIUCD application in Bundelk hand region. J Evol Med Dent Sci. 2014;3:9518-26.

17. Vidyarama R, Nagamani T, Prasad U. PPIUCD as a long acting reversible contraceptive (Larc)-an experience at a tertiary care centre. IJSR. 2012;4:5-7.

18. Chen BA, Hayes JL, Hohmann HL, Perriera LK, Reeves MF, Creinin MD. A randomized trial of postplacental compared to delayed insertion of the levonorgestrel releasing intrauterine device after vaginal delivery. Obstet Gynecol. 2010;116(5):107987.

19. Mishra S. Evaluation of safety, efficacy, and expulsion of post-placental and intra-cesarean insertion of intrauterine contraceptive devices (PPIUCD). J Obstet Gynaecol India. 2014;64(5):33743.

20. Singhal S, Bharti R, Dewan R, Dabral A, Batra A. Sharma M, et al. Clinical outcome of postplacental Copper 380 a insertion in women delivering by cesarean section. JCDR. 2014;8(9):1-4.

Cite this article as: Gaur SS, Mendiratta S.

Postpartum intrauterine contraceptive device: evaluation of acceptance and complications. Int $\mathbf{J}$ Reprod Contracept Obstet Gynecol 2019;8:3219-22. 